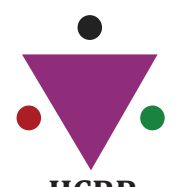

IJCRR

Section: Healthcare

Sci. Journal Impact

Factor: $5.385(2017)$

ICV: 71.54 (2015)

\title{
A Three and a Half Years Histopathological Study of Fibroepithelial Breast Lesions in a Tertiary Care Hospital
}

\section{Rohi Wani ${ }^{1}$, Sheema Sheikh ${ }^{2}$, Abdul Maajed Jehangeer ${ }^{3}$, Salma Bhat ${ }^{4}$, Isma Niyaz ${ }^{5}$, Bilques Khursheed ${ }^{6}$}

\begin{abstract}
'MBBS, MD (Path), Assistant Professor, Department of Pathology, Govt Medical College, Srinagar; ${ }^{2}$ MBBS, MD (Path), Associate Professor, Department of Pathology, Govt Medical College, Srinagar; ${ }^{3} \mathrm{MBBS}$, MS (Gen Surgery), Consultant Surgeon, Gousia Hospital, J\&K Health Services; ${ }^{4}$ MBBS, MD (Path), Associate Professor, Department of Pathology, Govt Medical College, Srinagar; ${ }^{5}$ MBBS, MD (Path), Senior Resident, Department of Pathology, Govt Medical College, Srinagar; ${ }^{6} \mathrm{MBBS}$, PG student, 2nd year, Department of Pathology, Govt Medical College, Srinagar.
\end{abstract}

\section{ABSTRACT}

Breast specimens are one of the most frequent entries in our department of pathology. Out of these surgical specimens, fibroepithelial lesions are received almost every day.

Aim: To study and provide an overview of fibroepithelial lesions of breast. Further to stratify and classify various fibroepithelial lesions into fibroadenomas and phyllodes tumor.

Methodology: All the 386 cases of fibroepithelial lesions received over a period of $31 / 2$ years from Jan 2015-June 2018 were retrieved and studied in detail. All the associated histological changes as also the clinical details were noted down.

Results: Out of the total 386 fibroepithelial lesions, there were 372 fibroadenomas and 14 phyllodes tumors. Among all phyllodes tumors there was a single case each of borderline phyllodes tumor and malignant phyllodes tumor.

Conclusion: Fibroepithelial lesions show a wide range of morphology. A strict histopathological assessment with classification leads to proper diagnosis and thus proper treatment in such cases.

Key Words: Fibroepithelial lesions, Fibroadenoma, Phyllodes tumor

\section{INTRODUCTION}

Fibroepithelial lesions are the common lesions of breast. They are morphologically and behaviourally heterogeneous tumor with different clinical behaviours and treatment protocols. These constitute the commoner fibroadenomas and the rarer phyllodes tumor ${ }^{1}$. Fibroadenomas are the commonest benign biphasic fibroepithelial neoplasms occurring in $2^{\text {nd }}$ and $3^{\text {rd }}$ decade of life ${ }^{2}$. Phyllodes tumor occurs in an older age group usually around 45-49 years of age ${ }^{3}$. Almost all of the phyllodes tumor are reported as fibroadenomas on Fine needle aspiration cytology (FNAC) since the clinical presentation, as also the cytology findings of these overlap.
Although higher grade phyllodes tumors are rare neoplasms but need urgent attention. Accurate diagnosis and grading of phyllodes tumors are important for patient management and prognosis, as grade broadly correlates with increasing local recurrence risk, and metastasis occurs only in malignant tumors $^{4}$

\section{MATERIALS AND METHODS}

This study is a descriptive, retrospective type of study done on the breast specimens received in our Histopathology department over a period of $3 \frac{1}{2}$ years (from Jan 2015- June

Corresponding Author:

Dr. Rohi Wani, MBBS, MD Path, Assistant Professor, Department of Pathology, Govt Medical College, Srinagar, Jammu \& Kashmir - 190010; Cell no: +919419080732; +917006596100; Email: rohiwani@gmail.com

ISSN: 2231-2196 (Print)

Received: 02.12 .2018
ISSN: $0975-5241$ (Online)

Revised: 19.12 .2018
Accepted: 30.12 .2018 
2018). All the breast cases which included lumpectomy, excision biopsies, tru cut biopsies, mastectomy specimens and blocks for review were included in the study irrespective of age and sex. Specimens were received in $10 \%$ formalin and were subjected to routine haematoxylin and eosin stains. Fibroepithelial lesions were segregated and studied in detail. Clinical data of patients was retrieved from medical records.

All the sections were studied in detail, clinical history was noted down and morphological diagnosis was made. Cases were clustered as fibroadenomas and phyllodes tumors. Necessary details and variations in histopathology were noted down. All these lesions were classified according to the WHO classification of tumors ${ }^{5}$ of breast and tabulated as such.

\section{RESULTS}

A total of 759 specimens of breast were received over this period of three and a half years. Out of these fibroepithelial lesions, fibroadenomas constituted the major portion constituting almost half of the total number of breast specimens. Thus the most common breast lesion diagnosed was a fibroadenoma accounting for 372 cases whereas phyllodes tumor was diagnosed in 14 constituting of one malignant phyllodes, one borderline phyllodes and 12 benign phyllodes tumors. A total of 386 cases of fibroepithelial lesions were encountered in this period.

\section{DISCUSSION}

Fibroepithelial lesions of breast are neoplastic proliferations of specialised stroma which secondarily distorts lobules and ducts, incorporating these within a well defined mass. Although the resulting lesions do contain epithelial components, but it is only the stromal component which is neoplastic. These lesions encompass a variety of benign and malignant lesions ranging from fibroadenoma to malignant phyllodes tumor ${ }^{6}$. They encompass a heterogeneous group of lesions that range from benign to malignant, each exhibiting differing degrees of stromal proliferation in relation to the epithelial compartment ${ }^{7}$.

These lesions comprise a morphologically and biologically spectrum of biphasic tumors with epithelial and stromal components that demonstrate widely variable clinical behaviour. Fibroadenomas are common benign tumors with a number of histologic variants, most of which pose no diagnostic challenge. Cellular and juvenile fibroadenomas can have overlapping features with phyllodes tumors and should be recognized. Phyllodes tumors constitute a spectrum of lesions with varying clinical behaviour and are graded as benign, borderline or malignant based on a set of histologic features according to recommendations by the World Health Organization (WHO) 4 .

Fibroadenomas are benign tumor masses arising from both the epithelium and stroma of breast consecutively. They constitute the most common breast lesions especially in young age groups. It arises from terminal duct lobular unit from the intralobular stromal mesenchymal cells (Fig 1), along with the hyperplasia of intralobular ductal and acinar epithelium ${ }^{2}$.

All the cases of fibroepithelial lesions in our study were fibroadenomas except the 14 phyllodes tumor cases. There was a wide age range of 13 to 50 years in our cases. Size varied from as small as less than $1 \mathrm{~cm}$ to as big as $10 \mathrm{~cm}$. There were three cases of fibroadenomatosis in which more than two fibroadenomas were resected from a single patient at one point of time from the same breast or contralateral breasts.

Grossly all the fibroadenomas were round, nodular, discrete firm swellings with cut surface showing homogenous firm greyish white surface with slit like spaces. Bilateral breast adenoma was seen in $10(2.6 \%)$ of cases.

A wide variety of proliferative changes can be seen in the epithelial components of fibroadenoma ${ }^{2,8}$. A lot of the common microscopic variations of fibroadenoma were encountered in our study also. Out of these simple fibroadenoma, which had no other pathological association was seen in $76 \%$ of cases. The most common pathological association was fibrocystic change seen in about $16 \%$ followed by adenosis which was seen in 13 of fibroadenomas (Table 1). The most frequent association of fibroadenoma with fibrocystic disease was similar to studies as that of Geethamala $\mathrm{K}$ et $\mathrm{al}^{2}$.

Epithelial hyperplasia was present in a total of 7 cases with mild hyperplasia in 4 and moderate hyperplasia in 3 cases. This is much less $(47 / 372)$ than was seen in a study by Geethamala K, et $\mathrm{al}^{2}$ and Kuijper et al $(43.9 \%)^{8}$. There were 2 cases each of complex fibroadenoma, fibroadenoma with apocrine metaplasia and Juvenile fibroadenoma. A single case of myxoid fibroadenoma, giant fibroadenoma and fibroadenoma with stromal hyalinisation was also seen

All these histological variants usually do not pose any problem with the diagnosis, however cellular and Juvenile fibroadenoma (Fig 2) have some overlapping features with benign phyllodes tumor and thus should be recognised since the course of disease and treatment is quite different from one another ${ }^{4,6,9}$. Although there are no clear cut boundaries but strict histologic assessment of features with classification ultimately reveal the correct diagnosis and thus provide useful clinical information ${ }^{10}$.

Phyllodes tumor is a rare fibroepithelial lesion as compared to fibroadenoma, with wide spectrum of morphology. It has risk of local recurrence and uncommon metastasis. Although 
microscopic distinction between fibroadenoma and phyllodes tumor especially benign phyllodes tumor is difficult, strict histologic assessment of a combination of histologic features with classification help to achieve the correct diagnosis and provide useful clinical information ${ }^{10}$.

Phyllodes tumors were classified according to three tier grading system of WHO classification into benign, borderline and malignant ${ }^{4}$ (Table2). Out of the total cases of 14 phyllodes tumor, $1(7 \%)$ was borderline, $1(7 \%)$ was malignant and the rest (12=86\%) were all benign (Fig $3 \& 4)$. There was another case of breast sarcoma but it was a primary case of Fibrosarcoma without any evidence of it arising from or any association with phyllodes tumor.

The value of FNAC in the diagnosis of phyllodes tumor has always remained controversial ${ }^{3}$. In all our cases of phyllodes tumor FNAC was done as a first line investigation and it was reported as fibroadenoma in 11 out of the 12 benign phyllodes tumors. Only in a single case of benign phyllodes tumor, it was reported as phyllodes tumor on cytology. There is a significant overlap of phyllodes tumor with fibroadenoma in cytological diagnosis and it's always difficult to diagnose phyllodes tumor on FNAC alone ${ }^{11}$. The sensitivity for diagnosing phyllodes tumors by FNAC is only $40 \%$, although increased sensitivity can be achieved by combining cytohistological and radiological results ${ }^{12}$. Clinical presentation of a patient giving a diagnostic clue towards phyllodes tumors rather than fibroadenoma should always be investigated through radiology and core needle biopsy which has high sensitivity since the surgical management is the mainstay and moreover local recurrence has been associated with inadequate local excision ${ }^{3}$.

In a study done by Karim et al, the clinical and pathological features of a large single institutional series of ethnically diverse patients with phyllodes tumours was done to determine which characteristics were predictive of outcome. Sixty five phyllodes tumors were analysed; 34 were benign, 23 borderline and eight malignant ( 34 low grade and 31 high grade PTs on a two tiered grading system). Out of these Nine patients $(15 \%)$ had local recurrences. A greater percentage of higher grade tumours recurred and women of Asian origin had a higher recurrence rate than those of non-Asian origin. The 5 year disease-free survival was $81 \%$ as also the time to recurrence was significantly lower in the high grade group. There were no metastases or deaths from disease. The mean age at diagnosis and the mean tumour volume, both significantly increased with grade. Thus tumour grade was the only parameter related significantly to outcome of these patients ${ }^{13}$.

In the benign phyllodes tumor, the size varied from smallest $4 \mathrm{~cm}$ to largest measuring $15 \mathrm{cms}$. The age varied from 17 to 45 years. One of the benign phyllodes tumors showed areas of tubular adenosis with foci of hyalinisation and fibrocystic changes in the adjacent areas.
Another phyllodes tumor was seen in a 30 years old female who presented with a huge swelling in her left breast. She had noticed it four months back as small swelling, with a history of recent rapid increase in size and had reached the present diameter of $10 \times 10 \mathrm{~cm}$. In the meanwhile patient had seeked medical help in which FNAC of the swelling was done and reported as diagnostic possibilities of either a ductal carcinoma with osteoclast type giant cells or ductal carcinoma with increased stromal cellularity. Ultrasonography was reported as Fibroadenoma- BIRADS II. Trucut biopsy was done and reported descriptively as Malignancy with fibromyxoid stroma. Radical mastectomy was performed and we received a huge mastectomy specimen measuring 20x16x7 cms with axillary tail measuring $14 \times 7 \times 4 \mathrm{cms}$. On cut section a huge growth measuring 10x10x6 $\mathrm{cms}$ was occupying all quadrants sparing just the portion of upper inner quadrant. Cut surface of growth was variegated having friable, necrotic and haemorrhagic areas. On microscopic examination it came out to be stromal cell tumor with pleomorphic cells showing moderate to marked atypia (Fig $3 \& 4$ ). The mitotic rate of $>5 / 10 \mathrm{hpf}$ was counted, although such high mitotic count was present in focal areas only. All the lymphnodes were free from tumor. Benign phyllodes tumor was identified in $70-80 \%$ of the serial sections. So the final diagnosis of borderline phyllodes tumor was given.

In our study a single case of malignant phyllodes tumor (Fig5) was seen. A young 25 years old female presented with swelling right breast. The duration of swelling was a few days only and tru cut biopsy was done straightway on the basis of clinical features and radiological suspicion of malignancy. It was reported as malignant phyllodes on biopsy and surgery (partial mastectomy was performed within days of diagnosis). Grossly we received a partial mastectomy specimen with a globular, greyish white, well circumscribed firm area measuring $7 \times 4 \times 3 \mathrm{cc}$. On cut section it was variegated with areas of hemmorhage. Microscopy revealed a pleomorphic cell population with mitotic rate of $>15 / \mathrm{hpf}$. There was also an area of malignant smooth muscle differentiation (Fig 5). The diagnosis of Malignant phyllodes tumor with Leiomyosarcomatous element was rendered. IHC was advised for confirmation and it came out positive for desmin and smooth muscle actin.

\section{CONCLUSION}

Fibroepithelial lesions of breast are one of the most common lesions especially in young females. Out of these fibroadenomas are quite common and the rarer phyllodes tumor can cause a lot of clinical concern. Moreover the need to differentiate fibroadenomas from phyllodes tumor due to the different surgical procedures required for these tumors and the tendency of malignancy in phyllodes needs to be considered seriously. 


\section{ACKNOWLEDGEMENT}

Authors acknowledge the immense help received from the scholars whose articles are cited and included in references of this manuscript. The authors are also grateful to authors / editors / publishers of all those articles, journals and books from where the literature for this article has been reviewed and discussed.

\section{Source of Funding: Nil}

Conflict of interest: Nil

\section{REFERENCES}

1. Daramola AO, Oguntunde OA, Awolola NA. Audit of fibroepithelial tumors of the breast in a Nigerian tertiary institution. Niger. J Clin Pract 2016; 19:645-8

2. Geethamala K, Vani BR, Murthy VS, Rhada M. Fibroadenoma: A harbour for various histopathological changes. Clin Cancer Investig J 2015; 4:183-7

3. Mishra SP, Tiwary SK, Mishra M, Khanna AK. Phyllodes Tumor of Breast: A Review Article. Hindawi Publishing Corporation. ISRN Surgery. Volume 2013, Article ID 361469, 10 pageshttp://dx.doi.org/10.1155/2013/361469

4. Krings G, Bean GR, Chen YY. Fibroepithelial lesions; The WHO spectrum. Semin Diagn Pathol 2017 Sep; 34(5):438-452

Table 1: Fibroadenomas with different morphological variations

\begin{tabular}{lll} 
Morhological variation & $\begin{array}{l}\text { Number } \\
(\mathbf{n = 3 7 2})\end{array}$ & $\begin{array}{l}\text { Percent- } \\
\text { age }\end{array}$ \\
$\begin{array}{l}\text { FA without any associated variation } \\
\text { FA with Fibrocystic change }\end{array}$ & 61 & 76 \\
FA with Adenosis & 13 & 16 \\
FA with epithelial hyperplasia & 7 & 3.4 \\
FA with apocrine metaplasia & 2 & 1.8 \\
Juvenile FA & 2 & 0.5 \\
Complex FA & 2 & 0.5 \\
Myxoid FA & 1 & 0.5 \\
Giant FA & 1 & 0.27 \\
FA with stromal hyalinisation & 1 & 0.27 \\
Total & 372 & 100 \\
\hline
\end{tabular}

5. Lakhani S, Ellis I, Schnitt S, et al.: WHO Classification of Tumours of the Breast, 4th ed. Lyon, IARC, Press, 2012

6. Giri D. Fibroepithelial Lesions; Arch Pathol Lab Med. 2009; 133:713-721

7. Tan BY, Tan PH. A Diagnostic Approach to Fibroepithelial Breast Lesions. Surg Pathol Clin. 2018 Mar; 11(1):17-42

8. Kuijper A, Mommers ECM, Wall E, van Diest PJ. Histopathology of fibroadenoma of the breast. Am J Clin Pathol 2001; 115:736-42

9. Yasir S, Nassar A, Jimenez RE, Jenkins SM, Hartmann LC, Degnim AC, Frost M, Visscher DW. Cellular fibroepithelial lesions of the breast: A long term follow up study. Ann Diagn Pathol. 2018 Aug; 35:85-91

10. Zhang Y, Kleer CG. Phyllodes Tumor of the Breast. Histopathologic Features, Differential Diagnosis, and Molecular/Genetic Updates. Arch Pathol Lab Med. 2016; 140:665-671

11. Tse GM, Ma TK, Pang LM, Cheung H. Fine needle aspiration cytologic features of mammary phyllodes tumors. Acta Cytol. 2002 Sep-Oct; 46(5):855-63

12. Ward ST, Jewkes AJ, Jones BG, Chaudhri S, Hejmadi RK, Ismail T. The sensitivity of needle core biopsy in combination with other investigations for the diagnosis of phyllodes tumours of the breast. Int J Surg. 2012; 10(9):527-31.

13. Karim RZ, Gerega SK, Yang YH, Spillane A, Carmalt H, Scolyer RA, Lee CS. Phyllodes tumours of the breast: A clinicopathological analysis of 65 cases from a single institution. Breast. 2009 Jun; 18(3):165-70.

Table 2: Three-Tiered Grading System for PhyllodesTumors Based on 2012 World Health Organization Classification

\begin{tabular}{|c|c|c|c|}
\hline $\begin{array}{l}\text { Histologic } \\
\text { Features }\end{array}$ & Benign & Borderline & Malignant \\
\hline $\begin{array}{l}\text { Stromal cel- } \\
\text { lularity }\end{array}$ & Mild & Moderate & Marked \\
\hline Stromal atypia & Mild & Moderate & Marked \\
\hline $\begin{array}{l}\text { Mitosis (per } 10 \\
\text { HPF) }\end{array}$ & 5 & $5^{-9}$ & 10 \\
\hline $\begin{array}{l}\text { Stromal over- } \\
\text { growth }\end{array}$ & Absent & Absent or focal & Present \\
\hline Tumor margin & Well-defined & $\begin{array}{l}\text { Well-defined/ } \\
\text { focalinfiltrative }\end{array}$ & Infiltrative \\
\hline
\end{tabular}




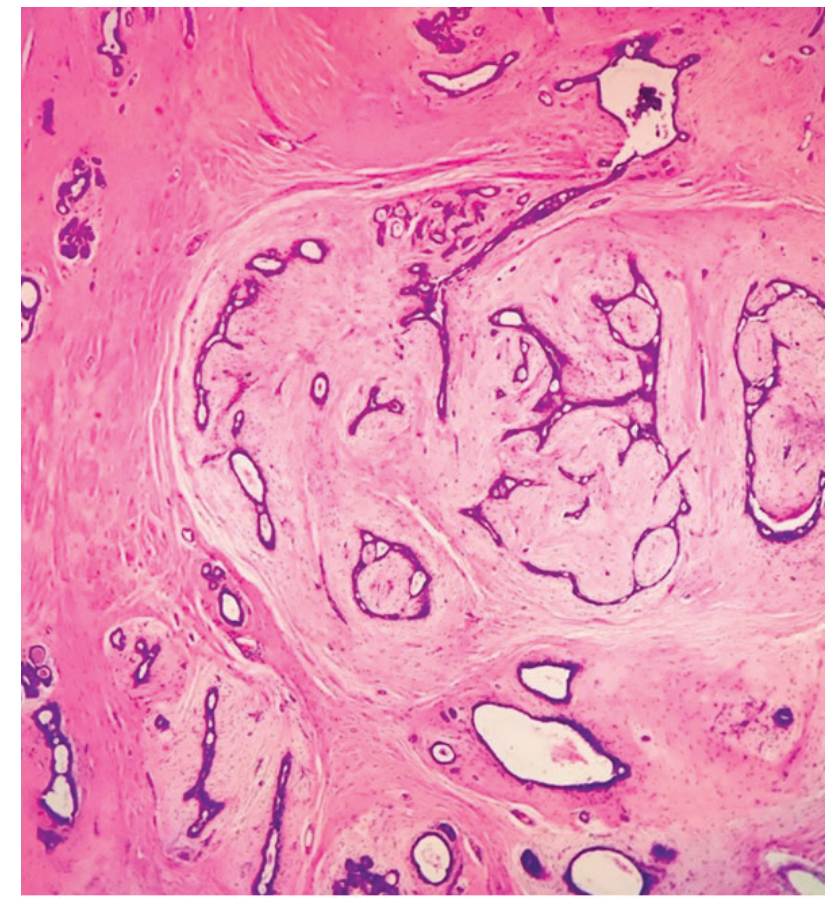

Figure 1: Photomicrograph showing Fibroadenoma. The proliferation and distinction of intralobular stroma is evident. (H\&Ex100).

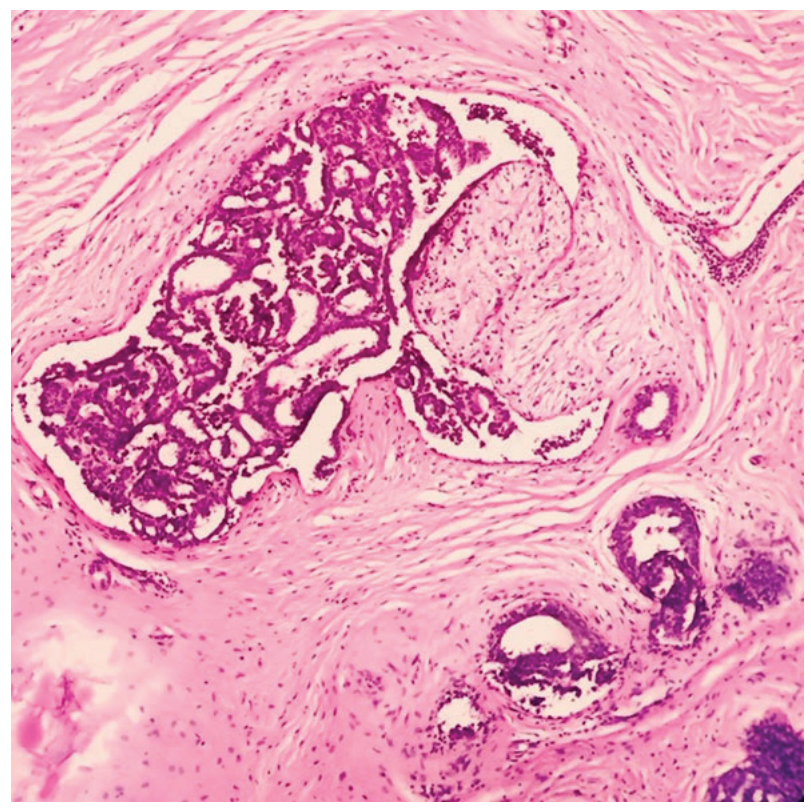

Figure 2: Moderate ductal hyperplasia (surrounded by stromal hyperplasia) in a case of Juvenile Fibroadenoma. (H\&Ex 100).

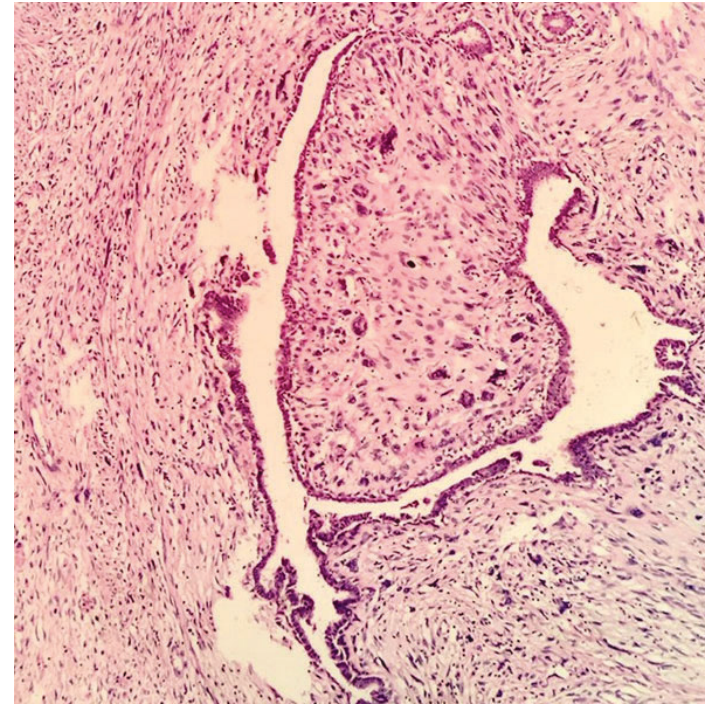

Figure 3: Phyllodes tumor showing tongue like protrusion formed by stromal overgrowth comprising of pleomorphic stromal cells. (H\&Ex100).

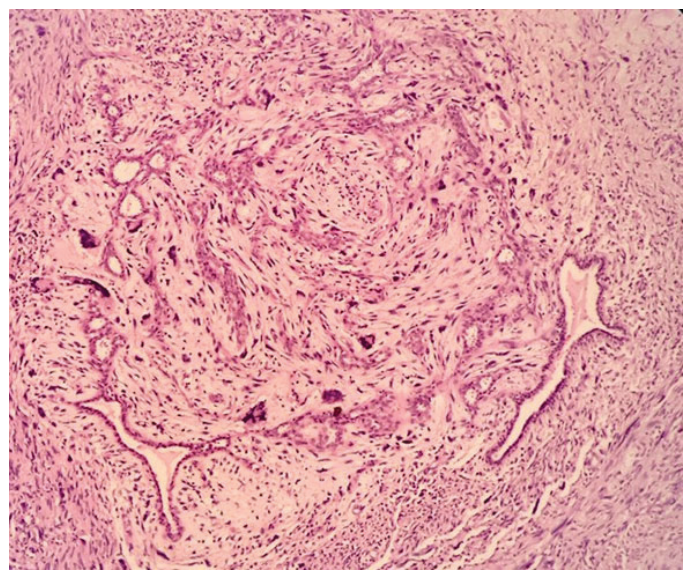

Figure 4: Phyllodes tumor with multinucleated giant cells within the stoma.(H\&Ex 100).

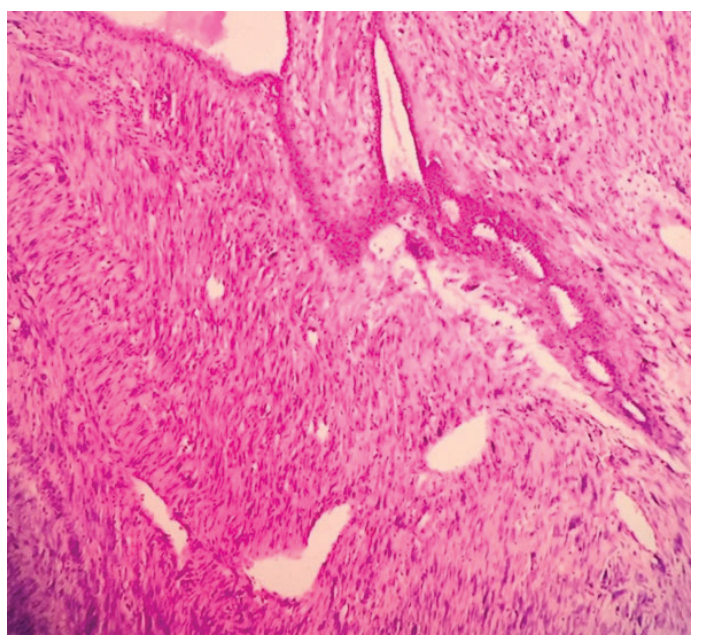

Figure 5: Malignant phyllodes tumor with adjacent Leiomyosarcoma component with herring bone pattern adjacent to the ducts. H\&Ex100. 